\title{
PRÁTICAS DE LINGUAGEM E ENSINO: LÍNGUAS, LITERATURAS E OUTROS CAMPOS DO SABER
}

\section{Andréa Rodrigues ${ }^{1}$, Maria Betânia Almeida Pereira ${ }^{1}$, Marcia Lisbôa Costa de Oliveira $^{1}$} ${ }^{1}$ Universidade do Estado do Rio de Janeiro (UERJ), São Gonçalo, RJ, Brasil
pensarev@gmail.com

Os textos que compõem o dossiê Práticas de linguagem e ensino: línguas, literaturas e outros campos do saber apresentam uma diversidade de práticas com linguagem, articuladas a pesquisas realizadas em vários Estados do Brasil e também fora dele. $O$ conjunto de artigos aqui publicados abrange o modo como essas práticas podem ser abordadas em documentos oficiais e materiais didáticos; na sala de aula de educação básica; nos programas de formação docente e em projetos de extensão.

No primeiro artigo, "A constituição histórica da leitura como objeto de ensino: 0 discurso oficial e o didático na década de 1930 no Brasil”, Alanne de Paula Barbosa e Washington Silva de Farias analisam como a leitura e o sujeito-leitor se constituíram historicamente no discurso pedagógico do primeiro programa de ensino de língua portuguesa de âmbito nacional, de 1931, e na coleção de manuais didáticos intitulada Programa de Português, de Júlio Nogueira, cuja organização segue as orientações daquele documento oficial. O estudo aponta a filiação retórica do programa oficial e nele reconhece matrizes das formas de pensar o ensino de língua e literatura no Brasil até a contemporaneidade, notadamente no que diz respeito à percepção dos textos literários como modelos e à reprodução como foco do ensino. Os autores tomam por base os fundamentos da Análise de Discurso de linha francesa e o campo da História das Ideias Linguísticas no Brasil. No momento em que se discute a Base Nacional Comum Curricular, cujas prescrições para o ensino fundamental foram homologadas em dezembro de 2017, enquanto a proposta para o ensino médio suscita grande resistência nas escolas e na academia, parece-nos bastante propícia a discussão trazida por este artigo.

Paulo Roberto Barbosa apresenta uma análise descritiva no artigo "Um estudo sobre os gêneros textuais no apostilado de língua portuguesa da rede pública paulista", a partir das concepções teóricas de gêneros textuais propostas por Bakhtin (2011 [1979]) e reinterpretadas pelo viés teórico-metodológico de Bronckart (2012 [1997]); Marcuschi (2008); Dolz e Schneuwly (2004). O foco de seu trabalho recai sobre o caderno apostilado do Estado de São Paulo, considerando o trabalho com os gêneros textuais, no nível do nono ano do Ensino Fundamental. Embora considere 
relevante a proposta deste caderno, o autor apresenta críticas quanto à escolha nem sempre abrangente dos gêneros.

Em "O texto autobiográfico em sala de aula do ensino fundamental”, Flávia Cavalcante Rocha e Aurea Suely Zavam discutem os resultados de uma sequência didática que teve como foco a produção de textos autobiográficos por estudantes do 9 o ano do Ensino Fundamental de uma escola pública de Fortaleza, Ceará. A fundamentação teórica articula os estudos de Bakhtin às proposições dos pesquisadores Bronckart, Dolz, Noverraz e Schneuwly, às reflexões de Brian Street acerca dos Letramentos Sociais e a perspectivas teóricas sobre a autobiografia. Os resultados indicam que os estudantes incorporaram em suas produções as marcas linguísticas próprias à autobiografia e que a mediação docente no processo de avaliação e reescrita das produções colaborou de forma decisiva para 0 aprimoramento dos textos. Sendo assim, a experiência apresenta interessante contribuição aos estudos sobre metodologias de ensino de língua numa perspectiva sociocultural.

No artigo "Produção textual dos alunos concluintes da educação básica: uma análise do estabelecimento da coerência em redações do ENEM", Marilúcia dos Santos Domingos Striquer analisa um conjunto de textos do gênero discursivo/textual produzidos por alunos do último ano do ensino médio, de escolas da rede pública de ensino atendidas pelo PIBID da Universidade Estadual do Norte do Paraná, e descreve a proposta de uma série de ações pedagógicas desenvolvidas a partir dessa análise. O estudo toma por base a Linguística Textual e o foco do projeto volta-se, sobretudo, para os aspectos que formam a coerência textual. $O$ artigo contribui também para destacar a importância de projetos como o PIBID para o aperfeiçoamento da educação básica de rede pública no Brasil.

Em "Avaliação: uma etapa fundamental no processo de escrita", Michele Batista da Silva e Taíse Simioni têm como foco a avaliação do processo de escrita de notícias no Ensino Fundamental, em pesquisa desenvolvida com alunos do 8ํㅜ ano de uma escola da Rede Municipal de Bagé, Rio Grande do Sul. As autoras explicitam o passo a passo das estratégias de avaliação desenvolvidas juntamente com o corpo discente, como é o caso da avaliação horizontal, estratégia apresentada por Antunes (2006). Durante o projeto, tanto a professora-pesquisadora quanto os alunos avaliaram todas as etapas de produção da notícia, desde o título e lead até a escrita do corpo textual, segundo critérios pré-estabelecidos. 
Elvira Lopes Nascimento e Luciana de Cassia Andrade discorrem sobre a importância de práticas inovadoras de ensino nos usos da linguagem, em contexto contemporâneo. Desta forma, no artigo "O Facebook mediando práticas docentes", defendem a ideia de que o gênero discursivo comentário do Facebook pode contribuir para o desenvolvimento da expressão oral e escrita discente na educação básica e apresentam pesquisa realizada com alunos de uma escola pública do Paraná. 0 estudo apoia-se no interacionismo sociodiscursivo, de Bronckart (2006), e trabalhos acerca do ensino-aprendizagem de gêneros textuais, de Schneuwly; Dolz (2004, 2009). Com base nestes aportes teóricos e em outros referenciados ao longo do estudo, as pesquisadoras compõem oficinas, elaborando assim um material didático significativo, que pode ser adaptado e aplicado por docentes.

Maria Angélica Lauretti Carneiro, em "A referenciação pronominal no discurso do professor: distanciamento e proximidade", analisa as significações produzidas pelas referenciações usadas nos discursos de duas professoras em aulas de leitura no Estado de São Paulo. A pesquisa apoia-se em concepções de Koch (2005; 2015); Koch e Marcuschi (1998); Marcuschi (1998); Apothéloz e Reichler-Beguelin (1995); Mondada (2005) e Mondada e Dubois (2003) e busca compreender os fenômenos referenciais nos cruzamentos entre linguagem, mundo e pensamento. A conclusão aponta para a ideia de que os mesmos pronomes usados em diferentes contextos discursivos podem produzir efeitos de sentido antagônicos e que a construção do distanciamento e da aproximação revelam concepções educacionais diversas.

Claudia Valéria Doná Hila e Vinicius da Silva Zacarias discutem, em "A contribuição da teoria da atividade para a construção de um APP sobre o gênero resenha de filme no PROFLETRAS", como o processo de formação do professor do Mestrado Profissional em Letras enfrenta desafios similares aos da formação inicial. Ao apresentar uma proposta de elaboração de um aplicativo sobre o gênero resenha de filme, desenvolvida por um professor em formação no PROFLETRAS da Universidade Estadual de Maringá (PR), o texto aborda as ações e operações mobilizadas pela professora-formadora, que desencadeiam novas operações no professor em formação, com base na Teoria da Atividade (LEONTIEV, 1998; 2001; 2004).

O artigo "Leitura e escrita: ações libertárias", das autoras Rosemary Lapa de Oliveira, Andréa Betânia da Silva e Maria Alba Guedes Machado Mello, traz uma abordagem teórico-metodológica a respeito de ações desenvolvidas em curso de extensão realizado nas dependências do Complexo Prisional Lemos Brito, localizado em Salvador, Bahia. Em consonância com as ideias de Paulo Freire (1996), Magda 
Soares (2004) e Roxane Rojo (2012), as autoras consideram a leitura e a escrita como "ações performáticas que ensejam um processo terapêutico de envolvimento do sujeito psicossocial com o meio no qual se encontra". Assim, a pesquisa enseja práticas pedagógicas voltadas para a inserção social e humana dos participantes envolvidos, por meio do contato com a pluralidade de gêneros textuais, pensando, sobretudo, na constituição de sujeitos leitores e produtores de conhecimento, de forma autônoma e crítica.

Na seção Resenha, este número traz três textos. Na primeira resenha, "Vinte anos - filme de Alice de Andrade", Andréa Rodrigues e Vivian Pizzinga apresentam uma breve análise do documentário Vinte anos, filme que mostra a trajetória de vida de três casais cubanos num intervalo de duas décadas. Com cenas filmadas em Cuba, nos Estados Unidos e na Costa Rica, o documentário recebeu prêmios no festival de Brasília e estreou no Brasil em 2018, tendo participado da Mostra Internacional de São Paulo e dos festivais internacionais de Miami, Guadalajara e Havana.

Na segunda resenha, "Língua de herança: língua brasileira de sinais - livro de Ronice Müller de Quadros”, Gigliola Duci Córdova ressalta a importância da obra para profissionais que atuam na área e também para quaisquer interessados na cultura surda, destacando que o livro traz informações sobre comunidades de língua de herança no Brasil e apresenta pesquisas realizadas, no Brasil e em outros países, com usuários de línguas de sinais.

$\mathrm{Na}$ terceira e última resenha, "Multimodalidades e leituras: funcionamento cognitivo, recursos semióticos, convenções sociais - livro de Angela Paiva Dionisio, Leila Janot de Vasconcelos e Maria Medianeira de Souza", Silvio Profirio da Silva e Josete Marinho de Lucena apresentam ao leitor uma obra que contempla as práticas de leitura de textos multissemióticos. No livro, baseado em pesquisas desenvolvidas no PIBID da Universidade Federal de Pernambuco, as autoras discutem o conceito de multimodalidades e abordam, entre muitas outras questões, as relações entre leitura e cognição, trazendo contribuições fundamentais para o trabalho com a leitura de textos dos mais variados gêneros e modos semióticos.

Com a proposta de seguir divulgando pesquisas e fomentando o debate sobre práticas com linguagens, Pensares em Revista abre, assim, o convite à leitura de seu novo dossiê.

As organizadoras 


\begin{abstract}
Sobre as organizadoras
Andréa Rodrigues

Doutora em Letras (PUC-Rio), com Pós-Doutorado na linha de pesquisa Memória e Linguagem (UNIRIO). Mestra em Linguística pela UFRJ. Professora do Programa de Mestrado Profissional em Letras (PROFLETRAS) e do Departamento de Letras da FFP-UERJ. Editora-chefe da Pensares em Revista. Atualmente, coordenada o PROFLETRAS da UERJ. Desenvolve pesquisas sobre ensino de língua e análise do discurso.

\section{Maria Betânia Almeida Pereira}

Doutora em Literatura Comparada (UFF); professora adjunta do Departamento de Letras, da FFP-UERJ.Coordena projetos de pesquisa ligados ao ensino de literatura, faz parte do Programa do Mestrado Profissional em Letras e da Especialização em Educação Básica, coordenando a modalidade Ensino de Língua e Literaturas de Língua Portuguesa. É editora ajunta da Pensares em Revista. Possui publicações nas áreas de Ensino e Literaturas.

\section{Marcia Lisbôa Costa de Oliveira}

Doutora em Letras (Ciência da Literatura) pela Universidade Federal do Rio de Janeiro (2002). Mestre em Letras (Ciência da Literatura) pela mesma universidade (1995). Professora Adjunta da Universidade do Estado do Rio de Janeiro, atuando na Faculdade de Formação de Professores, no Departamento de Letras. Membro do corpo docente do Mestrado Profisisonal em Letras (PROFLETRAS) e do Programa de Pós-Graduação em Letras e Linguística (PPLIN) na FFP-UERJ. Desenvolveu pesquisa de pós-doutorado sobre Multiletramentos e letramentos críticos em contextos periféricos, na FFLCH-USP.
\end{abstract}

